\title{
Extratos de nim no controle da Spodoptera frugiperda em milho
}

\section{Nim extracts on the control of Spodoppher frugiperda in corn}

\author{
Luiz Romário Uchoa ${ }^{1}$; Ivan Isidorio de Almeida Filho ${ }^{2}$; Joaci Pereira de Souza ${ }^{3}$; Cristian de França Santos ${ }^{4}$; Daniel Lima dos \\ Santos ${ }^{5}$
}

Resumo: O milho é uma cultura de grande importância econômica, no entanto, é bastante prejudicada pelo ataque da lagarta do cartucho, onde é utilizado o controle químico, que é tóxico à biodiversidade, necessitando-se desenvolver alternativas de controle natural. Assim, objetivou-se avaliar os efeitos de diferentes extratos derivados de nim no controle da lagarta-docartucho (Spodoptera frugiperda) em cultivo de milho irrigado. O experimento foi conduzido em condições de campo, no Instituto Federal de Educação, Ciência e Tecnologia do Ceará, Campus Iguatu. Para a realização do experimento, foi utilizado o delineamento em blocos ao acaso, com 6 tratamentos e 4 repetições totalizando 24 parcelas. Os tratamentos à base de nim utilizados foram: sem inseticida; frutos; folhas; folhas + sementes; óleo comercial e o inseticida químico. Avaliou-se o nível populacional das lagartas (S. frugiperda) assim como o comprimento das mesmas aos 18, 36, 54, 72 e 90 dias após o plantio. Paralelamente, realizou-se uma avaliação visual dos danos provocados ao cartucho e folhas expandidas das plantas de milho, com base em uma escala visual (escala Dives). O tratamento com os frutos do nim apresentou os melhores resultados em todas as variáveis analisadas, podendo ser utilizado em substituição de produtos químicos no controle da lagarta-do-cartucho. Para o número e comprimento das lagartas, os tratamentos com frutos e inseticida químico se destacaram dos demais. Em relação aos danos, os tratamentos com frutos, folhas, frutos mais folhas e inseticida químico não tiveram diferença estatística entre si. O tratamento com óleo comercial de nim não apresentou resultados satisfatórios.

Palavras-chave: Azadirachta indica; Lagarta-do-cartucho; Controle de pragas; Inseticidas naturais.

Abstract: Corn is a crop of great economic importance, however, it is greatly impaired by the attack of the carcass caterpillar, where chemical control is used, which is toxic to biodiversity, necessitating the development of natural control alternatives. Thus, the objective of this study was to evaluate the effects of different extracts derived from neem in the control of carpiaceous caterpillar (Spodoptera frugiperda) in irrigated corn cultivation. The experiment was conducted under field conditions at the Federal Institute of Education, Science and Technology of Ceará, Campus Iguatu. For the experiment, a randomized complete block design was used, with 6 treatments and 4 replications totaling 24 plots. The neem-based treatments used were: without insecticide; fruits; sheets; leaves + seeds; commercial oil and chemical insecticide. The population level of the caterpillars (S. frugiperda) as well as their length at 18, 36, 54, 72 and 90 days after planting were evaluated. In parallel, a visual evaluation of the damage to the cartridge and expanded leaves of maize plants was carried out, based on a visual scale (Dives scale). The treatment with the neem fruits presented the best results in all analyzed variables, and could be used in substitution of chemical products in the control of the carcass caterpillar. For the number and length of caterpillars, treatments with fruits and chemical insecticide stood out from the others. Regarding the damages, the treatments with fruits, leaves, fruits plus leaves and chemical insecticide did not have statistical difference between them. The treatment with neem commercial oil did not present satisfactory results.

Key words: Azadirachta indica; Cartridge crankcase; Pest control; Natural insecticides.

\footnotetext{
*Autor para correspondência

Recebido para publicação em 13/02/2018; aprovado em 10/03/2018

${ }^{1}$ Prof. Doutor - Instituto Federal de Educação, Ciência e Tecnologia do Ceará, Campus Iguatu; soupe@ zipmail.com.br.

${ }^{2}$ Graduado em Tecnologia da Irrigação e Drenagem do Instituto Federal de Educação, Ciência e Tecnologia do Ceará; Iguatu; luizromario.cdd@ gmail.com;

${ }^{3}$ Graduando em Tecnologia da Irrigação e Drenagem do Instituto Federal de Educação, Ciência e Tecnologia do Ceará; Iguatu;

fazenda.terraprometida@hotmail.com.

${ }^{4}$ Graduando em Tecnologia da Irrigação e Drenagem do Instituto Federal de Educação, Ciência e Tecnologia do Ceará; Iguatu, ivanfilho.acopiara@hotmail.com

${ }^{5}$ Graduando em Tecnologia da Irrigação e Drenagem do Instituto Federal de Educação, Ciência e Tecnologia do Ceará; Iguatu,dlsdaniel1035@ gmail.com
} 


\section{INTRODUÇÃO}

Considerada uma das culturas mais importantes para a agricultura brasileira, o milho (Zea mays L.) é cultivado principalmente em duas épocas distintas do ano, verão (safra) e outono (safrinha) (TOSCANO et al., 2012). No Brasil, esta cultura apresentou aumento significativo em tecnologias, refletindo em acréscimos de produtividade devido às variações nas regiões de cultivo, aliada principalmente à adaptação ao ambiente de determinadas cultivares (FARINELLI; FILHO, 2006). Segundo o oitavo levantamento realizado no mês de Maio pela companhia nacional de abastecimento (CONAB) para o milho, primeira e segunda safra 2017/2018 está prevista uma variação de 7,3\% na área plantada chegando a um total de 5.080,1 milhões ha ${ }^{-1}$ e uma produtividade de $5.169 \mathrm{~kg} \mathrm{ha}^{-1}$, sendo que a estimativa de produção total é de 26.260,2 milhões de toneladas. Para o milho segunda safra ou safrinha estima-se uma área a ser plantada de $11.564,9$ milhões ha $^{-1}$ variação de $4,5 \%$ sendo uma estimativa de produção total de 62.947,5 milhões t e uma produtividade de $5.443 \mathrm{~kg} \mathrm{ha}^{-1}$.

O milho é sem dúvida um dos cereais mais cultivados em todo o mundo, sendo responsável também por boa parte da alimentação humana e animal. Sua importância econômica é caracterizada pelas diversas formas de sua utilização, que vai desde a alimentação humana e animal até a indústria de alta tecnologia, em que a alimentação humana com derivados de milho, constitui fator importante no uso desse cereal. Por exemplo, no Nordeste do Brasil, o milho é a fonte de energia para grande parte da população do semiárido, outro exemplo está na população mexicana, que tem no milho o ingrediente básico para sua culinária. Sendo considerado o terceiro produto agrícola do mundo, com ampla distribuição mundial, tanto na produção quanto no consumo (LIMA et al., 2009; ZURE et al., 2011).

De acordo com as informações citadas anteriormente faz-se necessário o desenvolvimento de novas técnicas de manejo para aumentar a produção e qualidade do milho produzido. Dentre as técnicas de manejo, destaca-se o combate às pragas que atacam as lavouras causando perdas consideráveis na produção. Atualmente, são utilizados inúmeros inseticidas químicos no combate a essas pragas, produtos esses quando utilizados ajudam no controle das pragas mantendo uma boa produção, no entanto, os mesmos podem vir a causar graves problemas ambientais e à saúde humana (FIGUEIREDO et al., 2006).

Dentre as pragas que atacam o milho, destaca-se a lagarta-do-cartucho (Spodoptera frugiperda). Os sintomas de seu aparecimento podem ser observados com o surgimento das primeiras folhas do milho, onde é possível observar a postura dos ovos realizada pela mariposa do inseto, após a eclosão os dos ovos as lagartas começam a se alimentar gerando o sintoma conhecido como "folha raspada", com o seu desenvolvimento as lagartas tornam-se mais vorazes e começam a consumir partes maiores da folha perfurando a mesma, neste momento as lagartas são capazes de consumir completamente as plantas mais jovens podendo levar a morte das mesmas (TOSCANO et al., 2012).

Apesar de ter ação rápida e eficiente, o uso de produtos químicos pode desenvolver populações de pragas resistentes, o aparecimento de novas pragas ou a ressurgência de outras, além de ocasionar a morte dos inimigos naturais e a conversão de pragas secundárias em pragas primárias
(DALVI et al., 2011). Produtos químicos ameaçam a vida silvestre, podendo ocasionar desequilíbrio ecológico, tornando-se também uma ameaça à saúde humana, por isso a necessidade de alternativas que minimizem os efeitos adversos dos inseticidas sintéticos sobre o meio ambiente.

$\mathrm{Na}$ agricultura, o controle do ataque de pragas ou doenças pode ser obtido com o emprego de produtos naturais e o uso de inseticidas biológicos que não contaminem a planta, o homem ou o meio ambiente. Esses produtos chamados de defensivos alternativos ou naturais têm baixo impacto ambiental, sua ação benéfica não favorece o surgimento de patógenos resistentes, além de possuir baixa toxidade aos inimigos naturais e mínimo efeito sobre o meio ambiente e o homem (SILVA et al., 2008).

Produtos naturais referem-se a metabólitos ou compostos de origem natural de animais (microrganismos, artrópodes, répteis, toxina de cobras, etc.) ou vegetais (algas, plantas, etc.), esses compostos pertencem ao metabolismo secundário dos seus portadores, os mesmos apresentam algumas características peculiares, como por exemplo, não serem essenciais para o organismo que o produz, mas entrando em contraste com os produtos do metabolismo primário, como os carboidratos, lipídeos, aminoácidos e nucleotídeos (MANN, 1995).

Os inseticidas botânicos estão relacionados com o metabolismo secundário das plantas e são responsáveis pela defesa química das plantas contra o ataque de insetos herbívoros (CORRÊA; SALGADO, 2011). A extração do princípio ativo pode ocorrer de toda a planta ou de parte dela, podendo ser do próprio material vegetal, o qual normalmente é moído e transformado em pó, ou pela extração aquosa com solventes orgânicos (MENEZES, 2005). O efeito dos inseticidas botânicos sobre os insetos é variável, podendo ser tóxico, repelente, causar esterilidade, modificar o comportamento, o desenvolvimento ou reduzir a alimentação (MOSSINI; KEMMELMEIER, 2005). Os extratos podem ser obtidos de diversas plantas como alho, fumo, cavalinha, pimenta, nim e etc. Dentre os produtos citados anteriormente, o nim vem destacando-se no controle da Spodoptera frugiperda, sendo alvo de vários estudos e pesquisas (GOMES, 2015; MAZZONETTO et al., 2013).

O nim ou amargosa (Azadirachta indica A. Juss) é uma planta que apresenta alta concentração de azadiractina, um princípio ativo que vem demonstrando alta eficácia no combate de diversas pragas e doenças que atacam plantas e animais. A azadiractina foi um dos primeiros princípios ativos a serem isolados do nim e já provou ser o principal ingrediente no combate aos insetos (PARCKERT, 2009). Atribui-se a azadiractina cerca de $90 \%$ dos efeitos causados nos insetos, a qual é, utilizada como padrão de qualidade para utilização de óleos de nim de diversas procedências. A azadiractina não causa a morte instantânea dos insetos, porém, os impede de continuarem se alimentando. Além disso, interfere no seu desenvolvimento e já demonstrou ser um dos mais potentes reguladores de crescimento de insetos (VEANHOLI et al., 2012).

Os inseticidas naturais à base de nim são biodegradáveis, dessa forma, não deixam resíduos tóxicos nem contaminam no ambiente, esses inseticidas são citados na literatura por apresentarem ação repelente, anti alimentar, interferência na metamorfose, esterilidade, anormalidades anatômicas e interrupção do crescimento (MARTINEZ et al., 2001). 
Diante do exposto, objetivou-se avaliar os efeitos de diferentes extratos derivados de nim no controle da lagartado-cartucho (Spodoptera frugiperda) em cultivo de milho irrigado.

\section{MATERIAL E MÉTODOS}

O experimento ocorreu do dia 27 de Abril a 27 de Julho de 2016 sendo conduzido em área experimental, localizada no Instituto Federal de Educação, Ciência e Tecnologia do Ceará (IFCE), na Vila Cajazeiras, município de Iguatu, região Centro-Sul do estado do Ceará, a $6^{\circ} 23^{\prime} 31^{\prime \prime} \mathrm{S}$ de latitude, $39^{\circ} 15^{\prime} 55^{\prime}$ W de longitude e altitude de 226 m. A região está inserida numa zona climática, de acordo com a classificação de Köeppen, do tipo BSw’h' (clima quente e semiárido), com precipitação média anual de $870 \mathrm{~mm}$.

Antes do plantio foi realizada uma aração para revolver o solo e incorporar as plantas espontâneas. Foram coletadas amostras de solo na profundidade de 0-20 cm e enviadas para o Laboratório de Água, Solos e Tecidos Vegetais do IFCE Campus Iguatu (LABAS), cujos resultados encontram-se a seguir: $\mathrm{pH}=6,2 ; \mathrm{M} . \mathrm{O}=10,2$ g.kg $\mathrm{kg}^{-1} ; \mathrm{P}=15,65 \mathrm{mg} \cdot \mathrm{dm}^{-3} ; \mathrm{K}=$ 3,59 mmolc.dm ${ }^{-3} ; \mathrm{Ca}=22,7$ mmolc. $\mathrm{dm}^{-3} ; \mathrm{Mg}=16,0$ mmolc. dm ${ }^{-3}$.

Para realização do experimento, foi utilizado o delineamento de blocos ao acaso, com 6 tratamentos e 4 repetições totalizando 24 unidades experimentais. Cada unidade experimental foi composta por seis linhas com $5 \mathrm{~m}$ de comprimento cada, com espaçamento entre unidades de $1,0 \mathrm{~m}$. Os tratamentos consistiram em: testemunha (sem aplicação de inseticida natural ou químico), frutos (extrato aquoso dos frutos), folhas (extrato aquoso das folhas), frutos mais folhas (extrato aquoso dos frutos mais folhas), óleo de nim (óleo comercial de nim), e químico (controle químico).

O plantio foi realizado no dia 27 de abril de 2016, de forma manual, em covas de aproximadamente $5 \mathrm{~cm}$ de profundidade, espaçadas em $0,8 \mathrm{~m}$ entre linhas e $0,2 \mathrm{~m}$ entre plantas, onde foram colocadas de 1 a 2 sementes por cova, de milho híbrido categoria S-1. Após três dias da germinação foi realizado um desbaste das plantas a fim de se manter 25 plantas por linha e um total de 3.600 plantas na área. A área útil foi composta pelas 4 linhas centrais com 4 metros de comprimento em cada parcela. $\mathrm{O}$ controle das plantas espontâneas ocorreu de forma manual por meio de capinas frequentes. Para manter o controle das mesmas, evitando assim a competição por nutrientes, água e luz, além de facilitar a locomoção na hora de coletar as plantas para análise.

A determinação do momento da aplicação dos inseticidas a base de nim, assim como o número de aplicações necessárias foram determinadas com base na metodologia proposta por Viana et al. (2006). Já o inseticida químico foi aplicado foi aplicado conforme indicação do fabricante. A aplicação dos tratamentos foi realizada no período vespertino após as 16:00 horas por meio de pulverização manual, utilizando bomba costal de 20 litros. A primeira aplicação dos inseticidas a base de nim e do químico ocorreu aos, oito DAP do milho. Sendo que a segunda aplicação dos inseticidas a base de nim ocorreram treze dias DAP. Já a terceira e última aplicação dos produtos a base de nim e a segunda do produto químico ocorreram aos dezoito DAP.

Para obtenção dos extratos foi adotada a metodologia proposta por Viana et al. (2006). Após a secagem, as folhas e frutos foram levados ao Laboratório de Água, Solos e Tecido Vegetal (LABAS) do IFCE, Campus Iguatu, as quais foram moídas e armazenadas em local fresco e seco.

Para obtenção do extrato aquoso das folhas e dos frutos foi adicionado $50 \mathrm{~g}$ para cada litro de água, já para o extrato de folhas mais frutos adicionou-se $25 \mathrm{~g}$ de cada em $1 \mathrm{~L}$ de água, deixando ambos em repouso por 12 horas. O recipiente não foi completado com o extrato até a borda, para não transbordar, devido à fermentação das folhas e sementes. $\mathrm{O}$ óleo comercial de nim e o inseticida químico foram adquiridos em casa agropecuária do município e dissolvidos de acordo com as recomendações do fabricante. Antes da aplicação dos tratamentos à base de nim, realizou-se uma filtragem manual dos extratos, usando tecido de algodão para realizar a filtragem e evitar o entupimento do equipamento a ser utilizado na pulverização. Adicionou-se também um adjuvante aos extratos na proporção de $352 \mathrm{ml}$ para cada 100 L de calda na hora da aplicação, para boa aderência dos extratos as folhas do milho.

A coleta dos dados sobre o nível populacional e comprimento das lagartas foram realizados aos 18, 36, 54, 72 e 90 DAP, sendo coletadas cinco plantas por parcela, que foram levadas ao laboratório. No laboratório, as lagartas foram retiradas das plantas identificadas e separadas as da espécie Spodoptera frugiperda, sendo em seguida, contado o número e feita a medição das mesmas utilizando uma régua graduada em centímetros. Foi realizada uma transformação do número de lagartas de acordo com a Equação 1.

Paralelamente foi realizada uma avaliação visual de danos no cartucho das plantas de milho com base em escala visual proposta por Dives e Williams (1992) atribuindo notas de 1 a 9 de acordo com o nível de danos que consistem em: 1De nenhum dano até 3 lesões muito pequenas nas folhas do cartucho; 2 - Lesões muito pequenas e pequenas circulares nas folhas do cartucho, 3 - Pequenas lesões circulares e algumas pequenas lesões alongadas de até $1,3 \mathrm{~cm}$ de comprimento nas folhas do cartucho; 4 - De 4 a 7 lesões alongadas, pequenas ou médias de 1,3 a $2,5 \mathrm{~cm}$ com algumas folhas do cartucho e folhas expandidas; 5 - De 4 a 7 lesões alongadas grandes, maiores que $2,5 \mathrm{~cm}$ de comprimento em algumas folhas do cartucho e folhas expandidas e/ou alguns furos pequenos a médios, de formato uniforme a irregular (membrana consumida) no cartucho e nas folhas expandidas; 6 - De 4 a 7 lesões em várias folhas do cartucho e expandidas e/ou vários furos uniformes a irregulares nas folhas do cartucho e expandidas; $7-8$ ou mais lesões alongadas de todos os tamanhos presentes na maioria das folhas do cartucho, além de muitos furos médios a grandes de formato uniforme a irregular nas folhas do cartucho e expandidas; 8 8 ou mais lesões irregulares de todos os tamanhos, presentes na maioria das folhas do cartucho, além de muitos furos médios a grandes, de formato uniforme a irregular nas folhas do cartucho e expandidas; 9 - Cartucho e folhas expandidas quase ou totalmente destruídos.

$\sqrt{x+1}$

Eq. (1)

Em que: $\mathrm{x}$ - é a variável; 1 - constante

Os resultados das avaliações foram submetidos a análises de variância por meio de software SISVAR 3.01 (FERREIRA, 2000). Utilizou-se o teste de Tukey ao nível de $5 \%$ de probabilidade para comparação das médias. 


\section{RESULTADOS E DISCUSSÃO}

Houve diferença significativa entre os tratamentos testados apenas no trigésimo sexto DAP (Tabela 1). Sendo que o tratamento com frutos foi o único a se diferenciar da testemunha (sem aplicação de inseticida natural ou químico), no entanto, o mesmo não apresentou diferença estatística dos demais tratamentos à base de nim ou do inseticida químico.

$\mathrm{O}$ tratamento com frutos do nim indica que as sementes se destacam por apresentar uma quantidade expressiva de óleo, o qual possui uma maior concentração do princípio ativo azadiractina, sendo associada a maioria dos efeitos sobre os insetos. A azadiractina é o principal composto da planta de nim com ação sobre os insetos, sendo os frutos, a sua principal fonte além da casca e das folhas, ela tem sido considerada a substância responsável pela atividade inseticida, atuando sobre os insetos como repelente e antialimentar, interferindo nos hormônios reguladores do crescimento, na metamorfose e na reprodução (VIANA et al., 2005). O potencial inseticida de inúmeros óleos essenciais de plantas está relacionado ao seu efeito de repelência, redução na oviposição e deterrência de espécies de pragas (BARROS et al., 2010).

Diferenciando-se do tratamento com frutos, as folhas tiveram menor eficiência dentre os produtos naturais à base de nim, isso pode ser atribuído principalmente a menor quantidade de azadiractina presente nas folhas (VIANA et al., 2010). Viana et al. (2006) ao estudarem os efeitos de extratos das folhas de nim, no controle e desenvolvimento da Spodoptera frugiperda, constataram uma mortalidade de $84 \%$ das lagartas quando usado $54 \mathrm{~g}$ do pó das folhas para cada litro de água, sendo que na dose $150 \mathrm{~g}$ por litro a mortalidade das lagartas chegou a $100 \%$ dos indivíduos.

Tabela 1. Número médio de lagartas Spodoptera frugiperda em plantas de milho submetidas a diferentes extratos de nim e inseticida químico.

\begin{tabular}{llllll}
\hline \multirow{2}{*}{ Tratamentos } & \multicolumn{5}{c}{ Dias após o plantio } \\
\cline { 2 - 6 } & 18 & 36 & 54 & 72 & 90 \\
\hline Testemunha & $1,04 * \mathrm{a}$ & $1,67 \mathrm{~b}$ & $0,98 \mathrm{a}$ & $1,14 \mathrm{a}$ & $1,02 \mathrm{a}$ \\
Frutos & $0,90 \mathrm{a}$ & $1,00 \mathrm{a}$ & $0,81 \mathrm{a}$ & $1,21 \mathrm{a}$ & $0,71 \mathrm{a}$ \\
Folhas & $0,94 \mathrm{a}$ & $1,47 \mathrm{ab}$ & $0,88 \mathrm{a}$ & $1,66 \mathrm{a}$ & $1,38 \mathrm{a}$ \\
Frutos+Folhas & $0,87 \mathrm{a}$ & $1,23 \mathrm{ab}$ & $0,78 \mathrm{a}$ & $1,31 \mathrm{a}$ & $0,83 \mathrm{a}$ \\
Óleo de nim & $0,86 \mathrm{a}$ & $1,20 \mathrm{ab}$ & $1,44 \mathrm{a}$ & $1,29 \mathrm{a}$ & $0,71 \mathrm{a}$ \\
Inseticida químico & $0,95 \mathrm{a}$ & $1,15 \mathrm{ab}$ & $1,32 \mathrm{a}$ & $1,11 \mathrm{a}$ & $1,00 \mathrm{a}$ \\
\hline \multicolumn{1}{c}{ CV (\%) } & 14,27 & 19,39 & 28,01 & 25,06 & 36,12 \\
\hline
\end{tabular}

*Valores seguidos de mesma letra na coluna não diferem pelo teste Tukey a 5\% de probabilidade.

O tratamento com inseticida químico não apresentou diferença estatística da testemunha, mostrando assim, pouca eficiência no controle do número de lagartas, fato este não esperado devido sua eficiência comprovada no mercado (Tabela 1). Segundo Mendes et al. (2011) a utilização de inseticidas químicos na tentativa de minimizar os prejuízos provocados por essa praga, muitas vezes, não produz o efeito esperado, o que acarreta no aumento de riscos de contaminação ambiental e a elevação de custos de produção, além de uma seleção natural de insetos resistentes.
Analisando o comprimento das lagartas, observou-se diferença estatística apenas aos 36 DAP (Tabela 2). Sendo que os tratamentos com os frutos do nim e o químico foram os únicos que apresentaram diferenças significativas em relação à testemunha, mas não diferiram entre si e dos demais tratamentos à base de nim. Resultado diferente foi encontrado por Veanholi et al. (2012) que ao estudarem o efeito de extratos de nim no controle da lagarta do cartucho, observaram que o efeito dos extratos foi significativo apenas aos 15 DAP.

Tabela 2. Comprimento médio das lagartas Spodoptera frugiperda em plantas de milho submetidas à diferentes extratos de nim e inseticida químico

\begin{tabular}{|c|c|c|c|c|c|}
\hline \multirow{2}{*}{ Tratamentos } & \multicolumn{5}{|c|}{ Dias após o plantio } \\
\hline & 18 & 36 & 54 & 72 & 90 \\
\hline Testemunha & $0,59 * a$ & $2,35 \mathrm{~b}$ & $0,48 \mathrm{a}$ & $0,88 \mathrm{a}$ & $0,63 \mathrm{a}$ \\
\hline Frutos & $0,32 \mathrm{a}$ & $0,61 \mathrm{a}$ & $0,17 \mathrm{a}$ & $1,01 \mathrm{a}$ & $0,50 \mathrm{a}$ \\
\hline Folhas & $0,38 \mathrm{a}$ & $1,69 \mathrm{ab}$ & $0,29 \mathrm{a}$ & $2,30 \mathrm{a}$ & $1,57 \mathrm{a}$ \\
\hline Frutos+folhas & $0,29 \mathrm{a}$ & $1,03 \mathrm{ab}$ & $0,12 \mathrm{a}$ & $1,23 \mathrm{a}$ & $0,25 \mathrm{a}$ \\
\hline Óleo de nim & $0,27 \mathrm{a}$ & $1,02 \mathrm{ab}$ & $1,26 \mathrm{a}$ & $1,27 \mathrm{a}$ & $0,95 \mathrm{a}$ \\
\hline Inseticida químico & $0,42 \mathrm{a}$ & $0,85 \mathrm{a}$ & $1,37 \mathrm{a}$ & $0,92 \mathrm{a}$ & $0,75 \mathrm{a}$ \\
\hline $\mathrm{CV}(\%)$ & 62,18 & 7,74 & 22,28 & 60,27 & 61,97 \\
\hline
\end{tabular}

*Valores seguidos de mesma letra na coluna não diferem pelo teste Tukey a $5 \%$ de probabilidade.

Apesar de não ter se diferenciado estatisticamente do tratamento com inseticida químico, o tratamento com os frutos (Tabela 2) apresentou maior influência no desenvolvimento das lagartas ao longo do tempo, indicando assim que, ocasionou menor crescimento das lagartas jovens na fase inicial da cultura. Segundo Carvalho et al. (2010), a falta do controle inicial da praga na cultura, é um dos fatores que podem comprometer o rendimento e a qualidade da produção, sendo que uma alta incidência do inseto pode determinar prejuízos à lavoura e à produção, com importante impacto econômico. A vantagem do uso de produtos naturais extraídos de plantas como a Azadirachta indica A. Juss (Meliaceae) é que podem ser aplicado mais de uma vez na lavoura, pois apresenta várias á vantagens em relação a produtos sintéticos, dentre as quais se destaca sua obtenção de fontes renováveis, sendo o mesmo de mais fácil degradação, 
além de não deixar resíduos em alimentos ou no meio ambiente (SOARES et al. 2011).

O tratamento com as folhas do nim não se diferenciou estatisticamente da testemunha, indicando uma menor influência no controle da $S$. frugiperda, devido uma variação na quantidade de azadiractina presente nas folhas, sendo necessário maior quantidade do pó para se obter bons resultados. Segundo Viana et al. (2006) a quantidade de azadiractina presente nas folhas de nim pode variar de acordo a época do ano, afirmam ainda que para as condições de Sete Lagoas, MG, a maior concentração dessa substância ocorre nos meses de março e abril, logo após o final do período chuvoso, e decresce acentuadamente no período de baixa precipitação pluviométrica (junho a setembro).

Aos 54 DAP os tratamentos com frutos, folhas, frutos mais folhas e inseticida químico não se diferenciaram estatisticamente entre si. Entretanto, os tratamentos com frutos e o químico se diferenciaram da testemunha e do óleo de nim mostrando melhores resultados (Tabela 3). Em regiões que são grandes produtoras de milho, tem-se uma maior dificuldade no controle da lagarta do cartucho devido ao cultivo de extensas áreas de milho, o que favorece o maior número de ciclos reprodutivos do inseto (MILANO et al., 2008).

O tratamento com os frutos do nim se destacou em relação à testemunha, mostrando ser favorável a sua utilização para controle da lagarta-do-cartucho. Segundo Viana et al., (2005), os frutos são a principal fonte de azadiractina, o composto com maior ação sobre os insetos. Os compostos extraídos dessa planta controlam mais de 400 espécies, incluindo insetos, nematoides, fungos, bactérias e mesmo algumas viroses (NATIONAL, 1992). Os produtos naturais derivados do nim têm a vantagem de possuir alta seletividade a insetos considerados pragas agrícolas, sendo que esses produtos são recomendados por diversos programas de manejo integrado de controle de pragas no mundo, principalmente por serem rapidamente degradados no solo e nas plantas e de não serem tóxicos ao homem e ao meio ambiente (FORIM et al., 2010).

$\mathrm{O}$ efeito positivo dos tratamentos com frutos e o inseticida químico aos 54 DAP (Tabela 3) é muito importante, pois é neste estádio com seis a oito folhas (estádios V6 a V8) desenvolvidas, conhecido como estádio do "cartucho" em que o ponto de crescimento e o pendão já estão acima do nível do solo e o colmo está iniciando um período de elongação acelerada (WEISMANN, 2008). A partir dos 54 DAP (estádios V9 a V17) ocorre o desenvolvimento dos órgãos florais (pendão e grãos em potencial) em cada planta, além da definição do tamanho da espiga quando ocorre a perda de duas a quatro folhas basais (WEISMANN, 2008). Sendo assim, um ataque do inseto nesse período pode ocasionar grandes perdas na lavoura. Por esse motivo, devem ser adotadas todas as táticas de controle de pragas, dando importância para o manejo adequado do sistema de produção, visando à preservação dos inimigos naturais presentes nas lavouras de milho (ARAÚJO et al., 2011; FIGUEIREDO et al., 2009).

Os resultados obtidos aos 54 DAP indicam menores danos provocados pelas lagartas, devido à eficiência dos produtos que atuaram não só como repelente, mas também influenciaram os hábitos alimentares da praga. Nas plantações de milho, a referida praga causa perda de até $20 \%$ na produção de grãos, quando o desfolhamento ocorre próximo à floração, normalmente as lagartas atacam o "cartucho" da planta, consumindo grande parte das folhas antes destas se abrirem (CARVALHO, 2008). Segundo Barros et al. (2010) um dos principais fatores que contribuem para o aparecimento da praga é a oferta de hospedeiros ao longo do ano, isso se deve ao cultivo sucessivo de culturas, como é o caso de milho e soja no verão, ou milho e sorgo na "safrinha". Sendo outro fator importante, o uso de alta tecnologia como no CentroOeste brasileiro, devido plantios de milho irrigado no inverno, aumenta a disponibilidade de hospedeiros nesse período.

Tabela 3. Valores médios dos danos causados pela Spodoptera frugiperda ao cartucho e folhas expandidas de plantas de milho submetidas à diferentes extratos de nim e inseticida químico.

\begin{tabular}{lccccc}
\hline \multirow{2}{*}{ Tratamentos } & \multicolumn{4}{c}{ Dias após o plantio } \\
\cline { 2 - 6 } & 18 & 36 & 54 & 72 & 90 \\
\hline Testemunha & $2,65^{*} \mathrm{a}$ & $4,35 \mathrm{a}$ & $3,20 \mathrm{bc}$ & $2,35 \mathrm{a}$ & $2,15 \mathrm{~b}$ \\
Frutos & $1,70 \mathrm{a}$ & $2,25 \mathrm{a}$ & $1,60 \mathrm{a}$ & $1,60 \mathrm{a}$ & $1,50 \mathrm{a}$ \\
Folhas & $2,05 \mathrm{a}$ & $2,75 \mathrm{a}$ & $1,85 \mathrm{ab}$ & $1,65 \mathrm{a}$ & $1,40 \mathrm{a}$ \\
Frutos+folhas & $2,20 \mathrm{a}$ & $2,75 \mathrm{a}$ & $1,85 \mathrm{ab}$ & $1,75 \mathrm{a}$ & $1,35 \mathrm{a}$ \\
Óleo de nim & $2,25 \mathrm{a}$ & $3,60 \mathrm{a}$ & $3,75 \mathrm{c}$ & $2,70 \mathrm{a}$ & $1,50 \mathrm{a}$ \\
Inseticida químico & $2,10 \mathrm{a}$ & $3,20 \mathrm{a}$ & $1,70 \mathrm{a}$ & $2,07 \mathrm{a}$ & $1,50 \mathrm{a}$ \\
\hline \multicolumn{1}{c}{ CV $(\%)$} & 26,87 & 29,67 & 26,07 & 28,03 & 11,01 \\
\hline
\end{tabular}

*Valores seguidos de mesma letra na coluna não diferem pelo teste Tukey a 5\% de probabilidade.

Diferenciando-se dos resultados obtidos anteriormente para número e comprimento das lagartas, o tratamento com folhas apresentou resultados satisfatórios para os danos, sendo inclusive, mais eficiente que o tratamento com o óleo de nim. Com esse resultado, percebe-se que o tratamento com folhas teve efeito sobre o hábito alimentar das lagartas, diminuindo ou inibindo o apetite das mesmas. Na literatura já foram relacionados vários efeitos dos extratos de nim sobre a $S$. frugiperda, dentre os quais podemos destacar: repelência, deterrância alimentar, interrupção no desenvolvimento e anormalidades anatômicas (MARTINEZ; EMDEN, 2001).
Aos 90 DAP, todos os tratamentos à base de nim diferenciaram estatisticamente da testemunha (Tabela 3), indicando influência sobre o hábito alimentar das lagartas, principalmente na fase final do ciclo da cultura, pois é nesse período que o controle da lagarta se torna mais difícil. Essa dificuldade pode ser explicada devido as mesmas se encontram em ciclo mais avançado e tendem a ocupar o cartucho das plantas de milho, dificultando a pulverização de inseticidas sobre as mesmas ou sobre as folhas, onde elas se instalam. Segundo Valicente e Tulher (2009), depois do segundo ou terceiro instar, as larvas começam a fazer buracos nas folhas, se alimentado em seguida do cartucho das plantas 
de milho, produzindo uma característica fileira de perfurações nas folhas.

Os tratamentos à base de nim também não se diferenciaram do tratamento com inseticida químico (Tabela $3)$. Este resultado mostra que, o uso de extratos aquosos do nim pode ser utilizado no controle da lagarta-do-cartucho favorecendo tanto a saúde humana quanto o meio ambiente. Diferindo-se do resultado anterior, Farinelli e Filho (2006), reportaram que o tratamento com produto químico refletiu sempre em menores danos retratando a importância da aplicação de inseticida, mediante o monitoramento, buscando opções por produtos seletivos.

\section{CONCLUSÃo}

O uso do extrato aquoso dos frutos do nim foi mais eficaz no controle da lagarta (Spodoptera frugiperda) que os demais tratamentos a base de nim, podendo ser utilizado como substituto do produto sintético.

\section{REFERÊNCIAS}

ARAÚJO, L. F.; SILVA, A. G. da; CRUZ, I.; CARMO, E. L. do; HORVATH, N. A.; GOULART, M. M. P.; RATTES, J. F. Flutuação populacional de Spodoptera frugiperda (J. E. Smith), Diatraea saccharalis (Fabricius) e Doru luteipes (Scudder) em milho convencional e transgênico Bt. Revista Brasileira de Milho e Sorgo, Rio Verde, v.10, n.3, p.205-214, 2011.

BARROS, E. M.; TORRES, J. B.; BUENO, Adeney F. Oviposição, desenvolvimento e reprodução de Spodoptera frugiperda (JE Smith) (Lepidoptera: Noctuidae) em diferentes hospedeiros de importância econômica. Neotropical Entomology, Pernambuco, v.39, n.6, p.996-1001, 2010.

CARVAlHO, E. V.; GONÇALVES, A. H.; AFFÉRRI, F. S. A.; DOTT, M. A.; PELUZIO J. M. Influência da lagarta-docartucho (Spodoptera frugiperda J.E.Smith), sobre híbridos de milho, no sul do Tocantins - Brasil. Revista Verde, Tocantins, v.5, n.5, p.152-157, 2010.

CARVALHO, R. P. L. Danos, flutuação da população, controle e comportamento de Spodoptera frugiperda (J.E. Smith, 1797) e suscetibilidade de diferentes genótipos de milho, em condições de campo. Piracicaba, 1970. 170p. Tese (Doutorado) - escola Superior de Agricultura "Luiz de Queiroz”, Universidade de São Paulo, São Paulo. 2008.

CONAB. Companhia nacional de abastecimento: Oitavo levantamento - Maio 2017 V.5 - SAFRA 2017/18- N.8.

CORRÊA, J. C. R.; SAlGADO, H. R. N. Atividade inseticida das plantas e aplicações: revisão. Revista Brasileira de Plantas Medicinais, Botucatu, v.13, n.4, p.500-506, 2011.

DALVI, L. P.; ANDRADE, G. S.; PRATISSOLI, D.; POLANCZYK, R. A.; MELO, R. L. Compatibilidade de agentes biológicos para controlar Spodoptera frugiperda (Lepidoptera: Noctuidae). Agrarian, Dourados, v.4, n.12, p.79-83, 2011.
DAVIS, F. M.; NG, S. S.; WILLIAMS, W. P. Visual rating scales for screening whorl-stage corn for resistance to fall armyworm. Technical bulletin-Mississippi Agricultural and Forestry Experiment Station (USA), 1992.

FARINELLI, R.; FILHO, D. F. Avaliação de dano de Spodoptera frugiperda (JE Smith, 1797) (Lepidoptera: Noctuidae) em cultivares de milho. Científica, Jaboticabal, v.34, n.2, p.197-202, 2006.

FERREIRA, D. F. 2000. Sistema SISVAR para análises estatísticas: Manual de orientação. Lavras: Universidade Federal de Lavras/Departamento de Ciências Exatas, 37p.

FIGUEIREDO, M. L. C.; CRUZ, I.; DIAS, A. M. P.; SILVA, R. B. Ocorrência do parasitoide Chelonus insularis no sul de Minas Gerais associado a lagartas de Spodoptera frugiperda na cultura de milho. Revista Brasileira de Agroecologia, Cruz Alta, v.4, n.2, p.4281-4284, 2009.

FIGUEIREDO, M. L. C.; MARTINS-DIAS, A. M. P.; CRUZ, I. Relação entre a lagarta-do-cartucho e seus agentes de controle biológico natural na produção de milho. Pesquisa Agropecuária Brasileira, Brasília, v.41, n.12, p.1693-1698, 2006.

FORIM, M. R.; MATOS, A. P.; SILVA, M. F. G. F.; CASS, Q. B.; VIEIRA, P. C.; FERNANDES, J. B. Uso de CLAE no controle de qualidade em produtos comerciais de nim: reprodutibilidade da ação inseticida. Quim. Nova, São Carlos, v.33, n.5, p.1082-1087, 2010.

GOMES, C. F. Uso do extrato da Azadirachta indica no das lagartas Spodoptera cosmioides e Spodoptera eridania (Noctuidae). 2015 150f. Tese (Doutorado em ciências biológicas) - Universidade de Rio Verde, Rio Verde. 2015.

LIMA, M. P. L.; OLIVEIRA, J. V.; MARQUES, E. J. Manejo da lagarta-do-cartucho em milho com formulações de nim e Bacillus thuringiensis subsp. aizawai. Revista Ciência Rural, Recife, v.39, n.4, p.1227-1230, 2009.

MANN, J. Secondary metabolism. Claredom: Oxford, 1995. MAZZONETTO, F. BET, J. Â. SOSSAI, V. L. M. CORBANI, R. Z. DALRI, A. B. Utilização de extrato de nim no controle da lagarta do cartucho do milho em campo. Revista Trópica: Ciências Agrárias e Biológicas, Maranhão, v.7, n.1, 2013.

MARTINEZ, S. S.; EMDEN, H. F. V. Growth disruption, abnormalities and mortality of Spodoptera littoralis (Boisduval) (Lepidoptera: Noctuidae) caused by azadirachtin. Neotropical Entomology, v.30, n.1, p.113-125, 2001.

MENDES, S. M.; LOPES, M. E.; WAQUIL, M. S.; WAQUIL, J. M. Respostas da lagarta-do-cartucho a milho geneticamente modificado expressando a toxina Cry 1A (b). Pesquisa Agropecuária Brasileira, Brasília, v. 46, n. 3, p. 239-244, 2011. 
MENEZES, E. L. A. Inseticidas botânicos: seus princípios ativos, modo de ação e uso agrícola. Seropédica, Rio de Janeiro: Embrapa Agrobiologia, 2005.

MILANO, P.; FILHO, E. B.; PARRA, J. R. P.; CÔNSOLI, F. L. Influência da temperatura na frequência de cópula de Anticarsia gemmatalis Hubner e Spodoptera frugiperda (J. E. Smith) (Lepidoptera: Noctuidae). Neotropical Entomology, Londrina, v.37, n.5, p.538-535, 2008.

MOSSINI, S. A. G.; KEMMELMEIER, C. A árvore nim (Azadirachta indica A. Juss): múltiplos Usos. Acta Farmacêutica, Bonaerense, v.24, n.1, p.48-139, 2005.

NATIONAL, R. C. Neem: a tree for solving global problems. 1.ed.Washington: National Academy Press, 1992. 139p.

SILVA, A. B.; BESERRA, E. B.; DANTAS, J. P. Utilização de Metarhizium anisopliae e extratos vegetais para o controle de Spodoptera frugiperda e Helicoverpa zea (Lepdoptera: Noctuidae) em milho. Engenharia Ambiental, Espirito Santo do Pinhal, v.5, p.077-085, 2008.

PARCKERT, E. D. T. Processamento de folhas de nim: inativação enzimática e secagem. 2009. Dissertação (Mestrado em Engenharia Química) - Universidade Federal de Uberlândia, Uberlândia. 2009.

SOARES, C. S. A.; SILVA, M.; COSTA, M. B.; BEZERRA, C. E. S. Ação inseticida de óleos essenciais sobre a lagarta desfolhadora Thyrinteina arnobia (Stoll) (Lepidoptera: Geometridae). Revista Verde de Agroecologia e Desenvolvimento Sustentável, Mossoró, v.6, n.2, p.154-157, 2011.

TOSCANO, L. C.; CALADO FILHO, G. C.; CARDOSO, A. M.; MARUYAMA, W. I.; TOMQUELSKI, G. V. Impact of insecticides on Spodoptera Frugiperda (Lepidoptera, Noctuidae) and its natural enemies on off-season maize in Cassilândia and Chapadão do Sul, State of Mato Grosso do Sul, Brazil. Arquivos do Instituto Biológico, v. 79, n. 2, p. 223-231, 2012.
VALICENTE, F. H.; TUELHER, E. S. Controle biológico da lagarta-do-cartucho, Spodoptera frugiperda, com baculovírus. Sete Lagoas: Embrapa Milho e Sorgo, Circular técnica, 2009. $14 \mathrm{p}$.

VEANHOLI, W. A.; MATEUS, G. P.; SANTOS, N. C. B.; BORGES, W. L. B.; SANTOS, W. T. C. Efeito de Extratos de Nim no Controle da Lagarta do Cartucho do Milho. In: XXIX Congresso Nacional De Milho e Sorgo - Águas de Lindóia - 26 a 30 de Agosto de 2012.

VIANA, P. A.; RIBEIRO, P. A.; NAZARET, ANDRÉIA M. Efeito de extratos aquosos de folhas secas armazenadas e de folhas verdes de nim na mortalidade larval de Spodoptera frugiperda (JE Smith, 1797) (Lepidoptera: Noctuidae), no milho. In: Congresso nacional de milho e sorgo, 28, Simpósio brasileiro sobre a lagarta do cartucho, 4, 2010, Goiânia. In: Potencialidades, desafios e sustentabilidade: resumos expandidos... Goiânia: ABMS, 2010. CD-ROM.

VIANA, P. A.; PRATES, H. T.; RIBEIRO, P.E. de A. Uso do extrato aquoso de folhas de nim para o controle de Spodoptera frugiperda na cultura do milho. 1.ed. Sete Lagoas: Embrapa Milho e Sorgo, 2006. 5 p. (Circular técnica, 88).

VIANA, P. A.; PRATES, HÉLIO T. Mortalidade de lagarta de Spodoptera frugiperda alimentadas com folhas de milho tratadas com extrato aquoso de folhas de nim Azadirachta indica. Revista Brasileira de Milho e Sorgo, Sete Lagoas, v.4, n.3, p.316-322, 2005.

WEISMANN, M. Fases de desenvolvimento da cultura do milho. Tecnologias e produção: Milho safrinha e culturas de inverno. Maracaju: Fundação MS, p. 31-38, 2008.

ZURE, G. E. O.; OLIVEIRA, V. M.; GOTARDO, M.; SANTOS, F. M. Produtividade de milho verde híbrido bm3061 sob diferentes tipos de adubação no plantio. Revista Verde de Agroecologia e Desenvolvimento Sustentável, Mossoró, v. 6, n. 2, p. 184-188, 2011. 